\title{
Electronic calendar as an element of digital IT-farm management
}

\author{
Victoria Sidorova and Evgeny Petrov* \\ Institute of Livestock Mechanization - Branch of the Federal State Budgetary Scientific Institution VIM, 108823 Moscow, Russia
}

\begin{abstract}
Management of on-farm processes in animal husbandry with an analogue primary accounting system (acts, journals, statements, certificates, cards, etc.) was carried out using paper, and later - electronic reporting forms. In the paper flow of zootechnical accounting, the document contained 70-250 records, the processing and maintenance of which took a lot of time: when entering 25-30 characters per minute, 1.5-2.5 hours; in electronic forms the number of printed characters has been reduced by 5-10 times, or up to 10-20 entries per document per minute. The transition from paper reporting to electronic reporting stabilized the speed of accounting and the number of personnel: 4 accountants were replaced by 1 computer operator, while expanding the database. The digitalization of the electronic calendar as a control element for a "smart" farm is becoming a new stage in optimizing work with document flow. The electronic calendar monitors economic and economic processes, time intervals, problems, automatically generates databases of production processes depending on the "key feature", for example, the indicator "live weight": animals that meet the condition $\mathrm{C}_{0}>\mathrm{Cc}$, who have collected the necessary live weight, pass to the next production cycle. Mass "C". Animals $\mathrm{C}_{0}=-\mathrm{Cc}$, that do not meet the requirement, are transferred to the emergency implementation group as economically ineffective for further fattening. The program of cyclical formation of production groups $\mathrm{C} i j$ depending on the weighing results, is described by a simulation model $U=$ $f(x, p)$, where $U$ is the state of the modeled component, $f$ are the main functional dependencies, $x$ are variables, $p$ are parameters.
\end{abstract}

\section{Introduction}

IT-technologies in animal husbandry in the form of software packages designed to combine on-farm operations into a coherent production system, are currently either absent or not perfect enough. They do not contribute to improving product quality, as well as optimizing production, which is the ability to choose the best option for organizing production activities [1].

For the stable sequential execution of production operations in the face of a significant increase in animal productivity, digital programs and plans based on IT platforms and applications are needed that will complement the traditional methods of efficient animal breeding with new technologies. Thus, the digitalization of the industry will allow to optimize the production system, namely, to combine the biological and engineering information (IT-technological) levels.

The use of appropriate algorithms combines genetic and technological parameters, environmental factors and information technologies, taking into account the degree of influence of individual traits and the possibility of their regulation. The unified model allows for the adoption of alternative solutions depending on the availability of available resources. To some extent, similar issues are considered by the programs of IAS "SELEX-Dairy Cattle", or IAS "SELEX-Meat Cattle".
Some others, however, are not informative enough, since their databases give priority to the breeding use of animals, without affecting their conditions feeding, maintenance, care, etc. [2].

An electronic calendar of production processes can become one of the elements of management of a modern "smart" farm in animal husbandry. It is designed to track economic and economic production processes, time intervals of work, possible problems, etc. using dates of electronic document flow.

In this case, the electronic document flow becomes part of the electronic calendar, and the electronic calendar itself becomes a system of entry and exit of information solutions for various production processes (livestock movement, formation of production groups, reproduction, sales of products, etc.).

Thus, for a single farm, an electronic calendar in the format of the digital economy is becoming an indispensable component of economic activity, which helps to systematize working hours and technological processes for efficiently running a business and generating optimal income.

\section{Literature review}

Technological processes on a livestock farm have certain patterns, which get their complete expression in the form of technical, technological and information models used

\footnotetext{
* Corresponding author: evg-petrov@mail.ru
} 
for the monitoring system. At the same time, both the improvement of the breeding and productive qualities of animals and the optimization of technological modes of economic activity are underway. They (models) help to justify the choice of optimal conditions for the implementation of genetic and available financial and technical resources in the form of programs for the effective management of the highly productive livestock sector. The programs for the development of cattle herds with the optimization of economic processes by modeling the parameters of the main factors of breeding and their components, contribute to the accelerated introduction of advanced technologies, the acceleration of genetic progress, efficiency of management at all stages of production [3, 4].

The main task of the digitalization of animal husbandry is the integrated monitoring of genetic, statistical, financial and technical and technological factors that contribute to the optimization of conditions for feeding and keeping animals, breeding, as well as the effectiveness of the introduction of new innovative solutions that contribute to improving the economy of the industry as a whole. The digitalization of the industry is the basis for further improvement of the theory and practice of breeding by introducing individual programs for herd development.

In the economic conditions of the digital economy, an electronic calendar on a farm is an indispensable component of economic activity. It helps to organize working hours and production processes when working with highly productive herds of animals, which have now become one of the main factors of competitive production. Essentially, the electronic calendar is an innovative digital management tool for livestock production.

The main feature of using information databases for modeling is the need to deal with debugged, optimal programming methods that have the ability to study numeric arrays, or subsets. Their main features, according to some authors [5] are:

- suitability for use - correctness, accuracy, correctness, interoperability, security;

- reliability - completeness, absence of errors, resistance to defects, recoverability, availability, readiness;

- efficiency - use of resources, applicability;

- practicality - comprehensibility, ease of use, learning performance, attractiveness;

- maintainability - ease of analysis, variability, stability, testability;

- mobility - adaptability, ease of installation, compliance, replaceability.

Kostrov B. V., Khrunichev R. V. (2017), Lapshina S. N., Berg D. B., Bazhenov I. A., Denisov A. D., Shaposhnikov V. A., Yakovleva T. I. (2016) and other authors [6] supplemented the above conditions of the modeling stages with the methods of system analysis: description of the model, building a dynamic model, drawing up functional diagrams, when setting initial conditions and parameters, changing conditions affecting these factors, determining the final process, classification the main parameters of the model and their optimization. In such programs, based on mathematical modeling, action algorithms are determined for each economic process or a specific production situation. Thus, such programs determine the optimal size and structure of the herd, the intensity of selection, etc.

In general, through the introduction of similarly edited programs and plans for breeding cattle, the greatest productive and economic effect can be obtained (Aligazieva P. A., Morin E. V., Shklyar A. V., Zakharova A. A., Wächter E. V. et al. [7]).

Evaluation of breeding programs carried out for individual breeds in different countries showed that the use of software packages, including those with the use of IT technologies, theoretically makes it possible to obtain genetic improvement of the populations of dairy and beef cattle up to $1.5-2 \%$ per year (Aligazieva P. A., Shklyar A. V., Yashin A. and others [8]).

For each program, there is a fixed set of source commands that are used directly or indirectly, as components in the construction of more complex programs and checks. Modeling in the field of population genetics, as in other areas of knowledge, essentially consists in their consistent implementation and optimization, that is, adaptation to specific conditions.

It is normal if the initial program has a limited set of commands. Modeling subsequent decisions is usually associated with the description of new commands that define the situation and the specifics of the program more fully. To run a command, it is necessary to develop its specification, that is, a sequence of composing algorithms that are used for more than one command. Of the general set of specifications, the most simple and short ones are used (Kutsevol P., Loginov V., Khorov E., Lyakhov A., Danilevich E.V., Evstratov A.R., Kukharenko N.I., Ovcharenko V.N., Poplavskii B.K., etc. [9].)

The length of program texts containing complex specifications is one of the difficulties of modeling since it is usually necessary to specify a precondition and a postcondition here. Usually the meaning of these conditions is different from the content of the programs themselves. The precondition describes the required situation; if the precondition is fulfilled, the verification work will definitely end. The postcondition distinguishes the most optimal among all situations. If the specification of checks in the selection command is defined incorrectly, then preconditions for verifying commands are again used as postconditions for checks until the postcondition of checks and the precondition of the commands match when choosing the optimal solution.

To model processes or situations, taking into account the proof of correctness of the program, it is necessary to conform between the program and the specification, which is subject to proof. The following principles of the program are usually highlighted:

- creation of a specification indicating the conditions under which it begins its work; 
- setting the sequence of command execution, by using the initially simplest;

- determination of the "branching" of the command or accounting for its implementation in various ways;

- use of a loop construction, that is, multiple execution of commands [10].

Cyclic instruction analysis, which is also one of the most important modeling tools, plays a central role in proving the correctness of programs. The need to use cyclical commands was substantiated in his calculations by Dijkstra E., who showed that they allow a large amount of calculations to be described in the form of a short program, according to the principle "yes, no", which fits the process: input:_"B","T"_"S"_"F" output, where "B" is an expression, "S" is a command to repeat the statement until it is true, "T", " $F$ " are program detailing operators.

Thus, various models of documentary search are compared for their relevance to the task: justification of the use of a vector model that most fully corresponds to a given search task in combination with statistical processing methods and is applicable for ranking documents when requested in an expression

$$
L i j=\left(b i j \in \frac{d i}{w i j}, t j \in d i=(0, t j) \forall i=1, \bar{n} ; j=1, \bar{D}\right),
$$

where $L i j$ is a vector describing the document $d i ; b i j-$ value $j$ of the position of the vector, which is equal to the weighting coefficient $w i j$, if $t j$ is in the document $i$ and " 0 " -otherwise; $D$-total number of dates $[11,12]$.

Thus, the IT program for the use of an electronic calendar on a livestock farm collects and analyzes the initial data for its implementation; design of software and hardware (systems, devices, parts, programs, databases) using automation tools; makes the development and execution of working technological documentation; applies "smart" control of compliance of developed projects and technical documentation with standards, specifications and other regulatory documents $[13,14]$.

\section{Materials and methods}

In the course of the study, methods of collection, study, systematization and processing of scientific information were used to optimize the algorithm multistage system, in order to substantiate the successful operation of an electronic calendar on a livestock farm, in accordance with the individual characteristics of each animal and technological groups of livestock when performing onfarm processes in general, as well as in certain particular areas of production.

The material of the research was the data of primary zootechnical registration in animal husbandry: pedigree registration cards, appraisal, quarterly reports, electronic forms of document flow, etc.

\section{Research results}

The main management of on-farm operations in animal husbandry under an analogue accounting system was carried out by using paper forms, and later electronic forms of reporting. Such reporting consisted of numerous acts, magazines, statements, certificates, animal cards, etc. with primary documentation of volume q, and $0.1 \mathrm{q}$.

With the paper form of accounting, the main carriers of information for livestock were the cards of breeding cows Mol-2 and breeding bulls Mol-2, registration and counting logs of livestock, lists of weighing and milking livestock, culling, sales, pedigree certificates, etc. In the paper workflow of production zootechnical accounting, only one document contained $70-250$ or more records, the processing of which and keeping them active took a lot of time, namely, when filling in 25-30 characters per minute, one form required up to 1.5-2,5:00.

The regularity of document management required processing a large amount of data presented in a form that was inconvenient for analysis. For example, a monthly plan was drawn up with a breakdown into 3-4 periods, if necessary by 5-6 to take into account the schedule of on-farm operations. The effectiveness of the analysis of production and, accordingly, the profitability of the enterprise depended on the cyclical nature of these periods. The electronic animal identification system, on the one hand, made it easier to fill out a paper report. On the other hand, it significantly expanded the volume of the database.

Thus, the number of printed characters on template electronic forms has been reduced by 5-10 times, or up to 10-20 entries per document per minute. The transition from a paper form of document management to an electronic one made it possible to stabilize the number of personnel. So, on the farms it was possible to release 4 accounting clerks, who were replaced by 1 computer operator (Fig. 1).

The daily routine on the farm and the duration of production operations are carried out in accordance with the biological characteristics of the animals for their optimal use. Let us consider the situation using the example of the technological process of feeding cattle. The use of the "digital electronic calendar", which included a database of both paper and electronic media in the form of operational tables, automatically processes daily business data, and their correction, if necessary, can be additionally carried out by the operator. That is, when using an electronic calendar, monitoring of technological processes, for example, the periods of seasonal insemination of mothers cows, receiving and rearing young animals, feeding and selling, is carried out by the IT information system of the farm, and the operator only prints out daily data on the movement of livestock and products. 


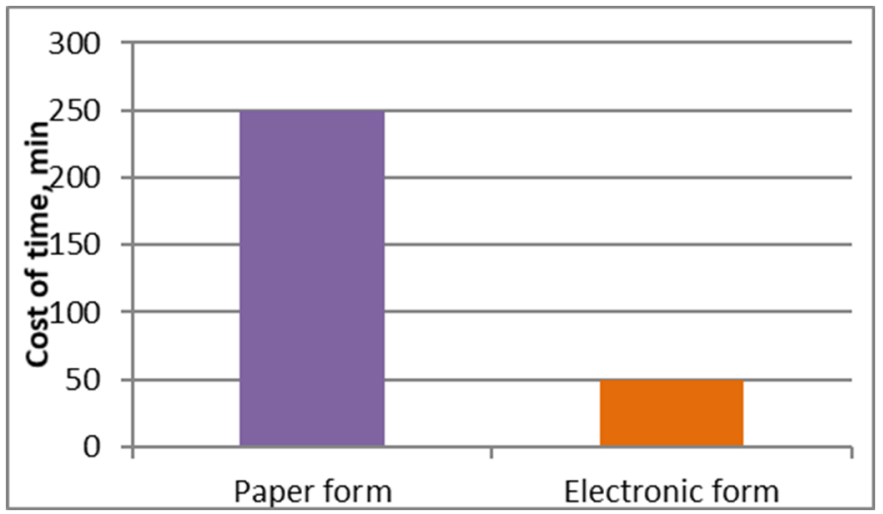

Fig. 1. Indicators of time spent on 1 paper and electronic document flow processing, min.

The program automatically creates a closed cycle of information processing. The database accumulates basic information: the origin of animals, development, complex assessment of the exterior, productivity, calving, service periods, inseminations, launches, etc. for each animal, which automatically move to the next date of the production cycle.

The use of a digital electronic calendar helps to optimize the operator's work: he does not need to enter data on the movement of each animal - it is carried out automatically, in accordance with the results of monthly weighing. In online mode, the operator receives readymade data on the movement of certain animals, which he transfers to the production department for execution.

The use of an electronic calendar on the farm is possible with the "cloud" storage of data, for example, filing cabinets.

Consider an example of electronic organization of production time on a smart farm. On a livestock fattening farm, the "live weight" indicator is a key moment, the "hot" key of the step-by-step action of the electronic calendar. After the operator (3) has entered this indicator at the birth of a calf, the process of its promotion through the database begins - the systematization of the herd composition according to the given parameters (2) is carried out in accordance with the indicators of the sensors (1) sent to the database of the computer network (Fig. 2)

The use of a digital electronic calendar allows the formation of a database automatically: all physiological groups of animals are automatically transferred to another day of the year and formed into conditional production groups, depending on the selected key accounting feature, for example, live weight. When the conditional and production groups are formed in an automatic mode, the animals that have gained the required live weight $\mathrm{C}_{0}>$ Ccpass to the next stage. Animals that do not meet the requirement of the task, namely $\mathrm{C}_{0}=-$ Ccare transferred to the emergency implementation group as ineffective (Fig. 3).

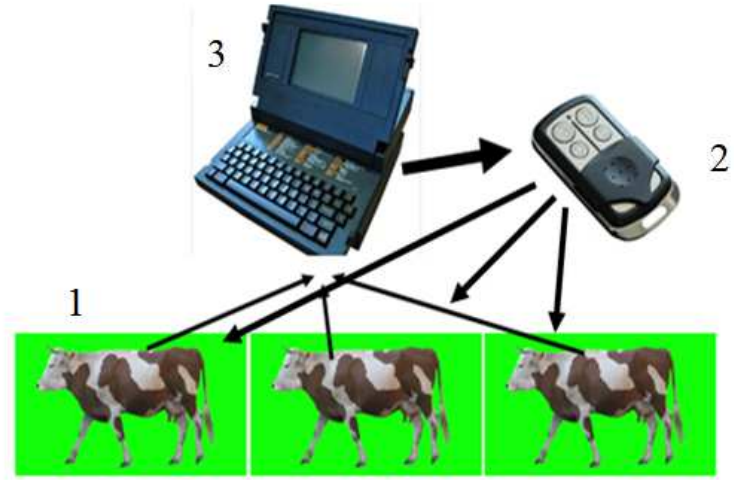

Fig. 2. Direction of sensor's signals from animal (1) to the control panel (2) and then to the scanner (3).

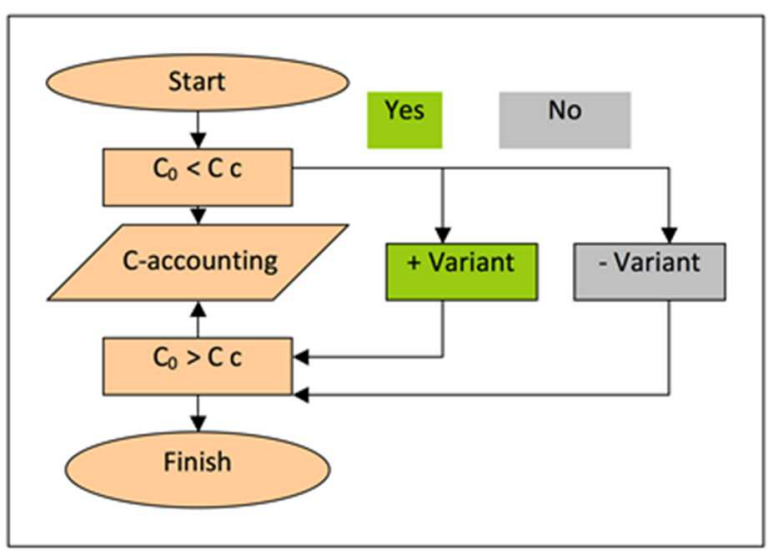

Fig. 3. Cyclogram of producing groups $\mathrm{Cij}$ depending on weighting's results formation

In general terms, a simulation model for managing a beef cattle farm includes: dividing the feeding process into components that are subsets of the main component; each component subset is described as a set of variables, parameters and functional dependencies modeled in accordance with indirect parameters (feeding, veterinary care, etc.); the description of the interaction of these subsets is carried out:

$$
U=f(x, p)
$$

where $U$ is the state of the modeled component, $f$ are the main functional dependencies, $x$ are variables, $p$ are the parameters of the model (Table 1, Fig. 4) 
Table 1. Function of the main subset

\begin{tabular}{|c|c|c|c|c|c|c|c|c|c|c|c|c|c|}
\hline $\begin{array}{c}\text { Time, } \\
\text { month }\end{array}$ & $\mathrm{x}$ & 1 & 2 & 3 & 4 & 5 & 6 & 7 & 8 & 9 & 10 & $\ldots$ & $\mathrm{x}_{\mathrm{n}}$ \\
\hline $\begin{array}{c}\text { Weight } \\
\text { gain, } \mathrm{g}\end{array}$ & $\mathrm{p}$ & 300 & 400 & 500 & 600 & 700 & 900 & 1000 & 1200 & 1400 & 1500 & $\ldots$ & $\mathrm{p}_{\mathrm{n}}$ \\
\hline
\end{tabular}

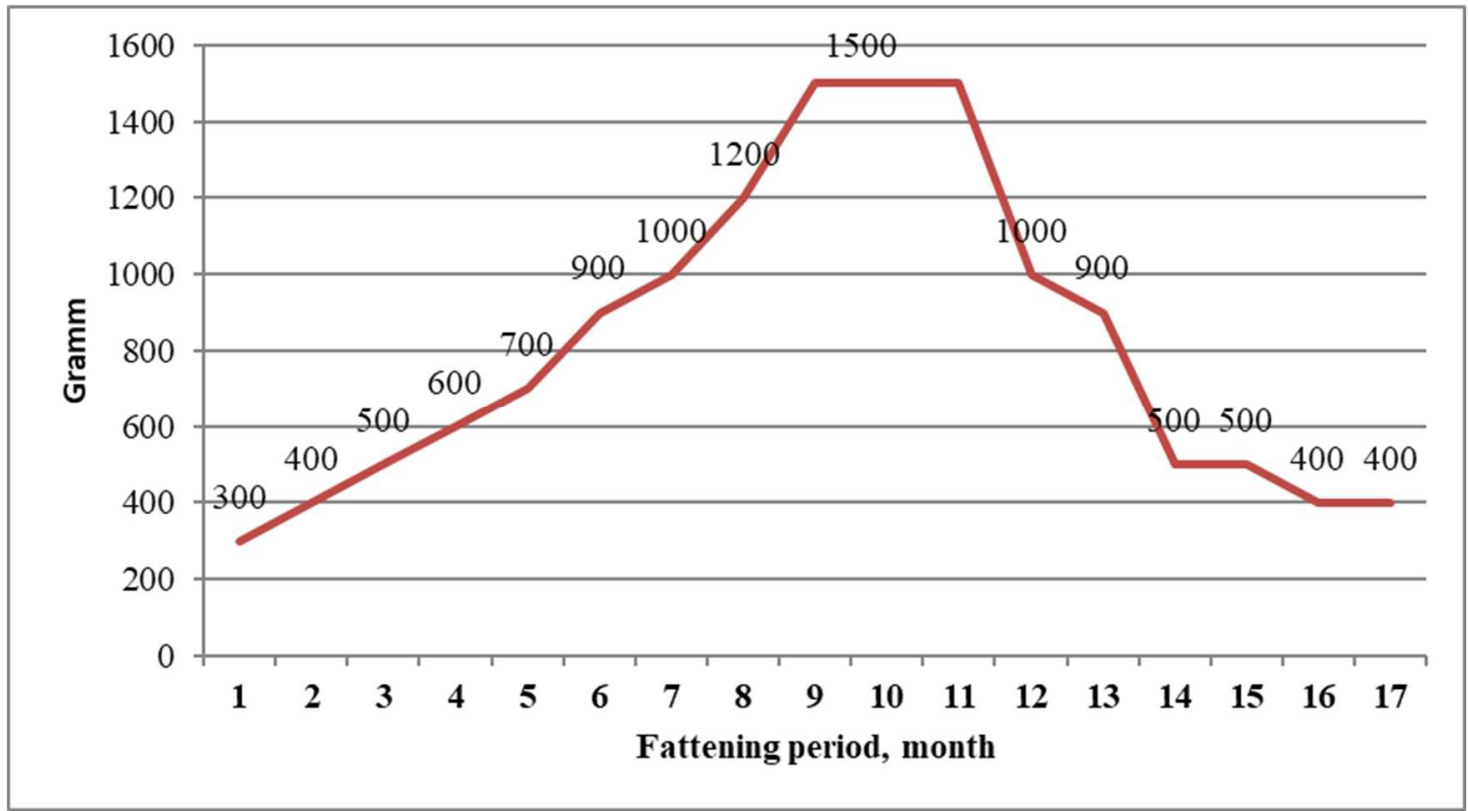

Fig. 4. Function $f i j(n)$ of fattening $(\mathrm{p} n)$ of livestock $(\mathrm{x} n)$ on Holstein cattle example

The production activity of an enterprise based on an electronic calendar can be specified by directions $m$ : feeding $m k$, culling $m b$, leaving $m g$, live weight qetc., which are distributed in a parallel matrix form in the application package in accordance with the coming calendar days.
When the conjugate variables change, the multiplier changes its state proportionally (Table 2). For scheduling based on timet, the simulation model takes the form:

$$
Y(t)=f i j(n) * 0,1 q(t) * C i j(t)(2)
$$

Table 2. Parameters of the main subset "live weight", $\mathrm{kg}$

\begin{tabular}{|l|c|c|c|c|c|c|c|c|c|c|}
\hline \multicolumn{1}{|c|}{ Time, days } & $t$ & 1 & 2 & 3 & 4 & 5 & 6 & 7 & $\ldots$ & $t_{n}$ \\
\hline $\begin{array}{l}\text { Parallel forms of functions (feed, } \\
\text { EKE) }\end{array}$ & $\mathrm{C}$ & 2 & 2 & 2 & 2 & 2 & 2 & 2 & & Cij \\
\hline Live weight, kg & $\mathbf{q}$ & $\mathbf{2 5}$ & $\mathbf{2 5 , 5}$ & $\mathbf{2 6}$ & $\mathbf{2 6 , 5}$ & $\mathbf{2 7}$ & $\mathbf{2 7 , 5}$ & $\mathbf{2 8}$ & $\ldots$ & $\boldsymbol{q}_{\boldsymbol{n}}$ \\
\hline "+" or "-" options & $\mathrm{z}$ & + & + & + & + & + & + & + & $\ldots$ & - \\
\hline
\end{tabular}

The variables $z$ of such a simulation model are the decisions made daily, for example, "to transfer animals of the $f$ jgroup with a live weight not lower than $f t 1$ to

the next stage of feeding on January 15 (16, 17, etc.)" (Table 3 ).

Table 3. Indicators of the main subset, heads

\begin{tabular}{|c|c|c|c|c|c|c|c|c|c|c|}
\hline Days & 1 & 2 & 3 & 4 & 5 & 6 & 7 & $\ldots$ & 365 \\
\hline \multicolumn{8}{|c|}{ Livestock from birth to sale } \\
\hline n1 & $\mathrm{n} 2$ & $\mathrm{n} 3$ & $\mathrm{n} 4$ & $\mathrm{n} 5$ & $\mathrm{n} 6$ & $\mathrm{n} 7$ & $\mathrm{n} 8$ & $\ldots$ & $\mathrm{n} 365$ \\
\hline- & $\mathrm{b} 1$ & $\mathrm{~b} 2$ & $\mathrm{~b} 3$ & $\mathrm{~b} 4$ & $\mathrm{~b} 5$ & $\mathrm{~b} 6$ & $\mathrm{~b} 7$ & $\ldots$ & $\mathrm{b} 122$ \\
\hline- & - & $\mathrm{d} 1$ & $\mathrm{~d} 2$ & $\mathrm{~d} 3$ & $\mathrm{~d} 4$ & $\mathrm{~d} 5$ & $\mathrm{~d} 6$ & $\ldots$ & $\mathrm{d} 94$ \\
\hline $\mathrm{n} 1$ & $\mathrm{~b} 1$ & $\mathrm{~d} 1$ & $\mathrm{~s}_{1}$ & $\mathrm{w}_{1}$ & $\mathrm{~h}_{1}$ & $\mathrm{v}_{1}$ & $\ldots$ & nbdij & $365-\mathrm{n}$ \\
\hline
\end{tabular}

In terms of the model, this will mean that the variables of the "ft 1 ", group, responsible for transferring animals to the new database, should take the appropriate values: time point - "January 15", operation

\footnotetext{
* Corresponding author: evg-petrov@mail.ru
} 
- "transfer", volume - n heads, that is, all The livestock is divided into groups, in accordance with the indicators of the weight counters for "transferred" and "removed" from the herd. That is, at birth, each animal is "registered" according to the main production parameters: "feeding", "maintenance", "care" and "veterinary processing", which determine the "feeding efficiency", the values of which are expressed in \% of the required value (Table. 4).

If the animal receives all the conditions provided for by the feeding system and gains the required live weight in each control period ("+" option, Fig. 5), it is sent to the next feeding period.

Table 4. Efficiency of fattening bull-calf Rodnik 12457 Holstein cattle breed

\begin{tabular}{|c|c|c|c|c|c|c|c|c|c|}
\hline \multirow{2}{*}{$\begin{array}{l}\text { Main production } \\
\text { processes from birth to } \\
\text { implementation }\end{array}$} & \multicolumn{9}{|c|}{ Days } \\
\hline & 1 & 2 & 3 & 4 & 5 & 6 & 7 & $\cdots$ & 365 \\
\hline Feeding, $\%$ & 100 & 100 & 100 & 100 & 100 & 100 & 100 & 100 & 100 \\
\hline Content, $\%$ & 100 & 100 & 100 & 100 & 100 & 100 & 100 & 100 & 100 \\
\hline Leaving, $\%$ & 100 & 100 & 100 & 100 & 100 & 100 & 100 & 100 & 100 \\
\hline Wind treatment, \% & 100 & 100 & 100 & 100 & 100 & 100 & 100 & 100 & 100 \\
\hline \multicolumn{10}{|c|}{ Feeding efficiency in accordance with the cyclogram of the formation of production groups } \\
\hline "+" Option & 100 & 100 & 100 & 100 & 100 & 100 & 100 & 100 & 100 \\
\hline “_" Option & 80 & 80 & 75 & 65 & 65 & 45 & 45 & 45 & $\begin{array}{c}\text { Disposal in } \\
\text { accordance with the } \\
\text { cyclogram (Fig. 4) }\end{array}$ \\
\hline
\end{tabular}

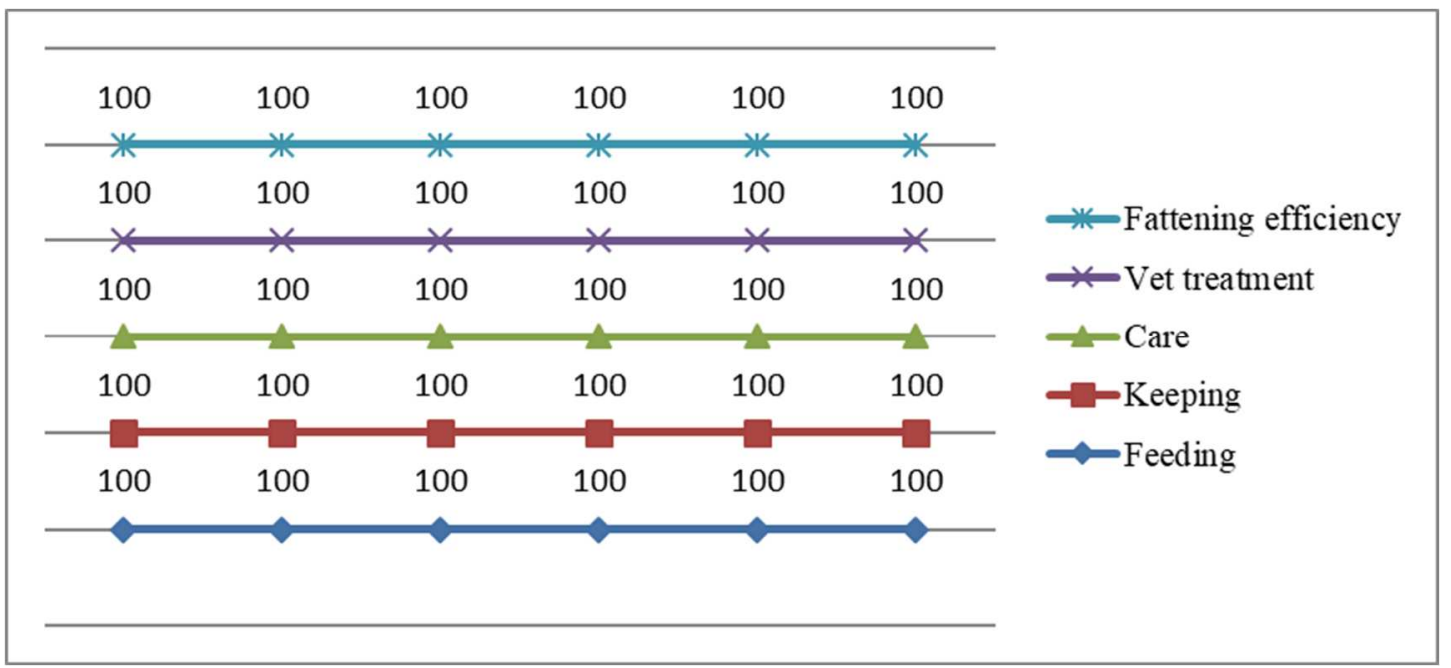

Fig. 5. The high efficiency of fattening

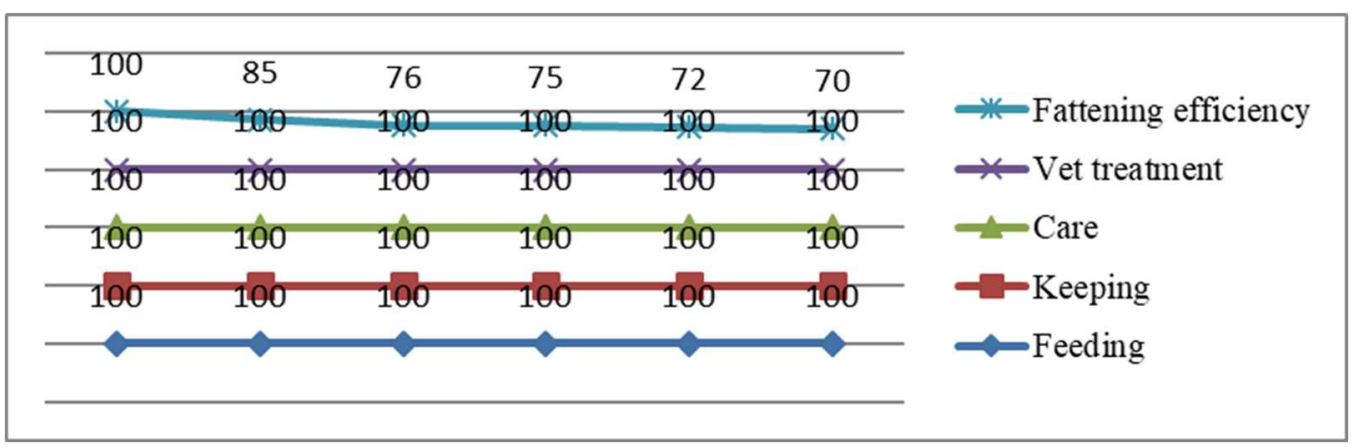

Fig. 6. The low efficiency of fattening

If the live weight does not meet the necessary requirements, the animal is sent for early implementation, as ineffective for further fattening ("“-” option, Fig. 6).
If these values change further, all model variables that are functionally dependent on them will be recalculated. That is, the variables responsible for the movement of animals within the herd will decrease by $t$ 1 "365 - $15=350$ days" in accordance with the database 
of increasing live weight of young animals. and decreasing days of feeding, which in turn is a set of model parameters. The specified parameters are recalculated depending on the weighing results (daily, weekly, monthly).

\section{Conclusion}

The use of an electronic calendar is important for the implementation of farms digitalization - information technology management of the herd in time $t$. This requires modeling, research and development of software systems and their components to control production processes. The functioning of the electronic calendar is carried out through the use of digital signal processing and generation devices, spreadsheets, measuring systems and interfaces.

The technological basis for the development of monitoring devices and diagnostics technologies for the selected parameters is the means of computing, microprocessor and telecommunications equipment for collecting IT information, transferring and managing data. The development of a simulation model for the digitalization of animal husbandry contributes to the monitoring of on-farm processes and provides the possibility of using a system for displaying information on monitors of various electronic devices for execution.

\section{References}

1. V.Y. Sidorova, A digital model of the ecological content of beef cattle, in: Proceedings of $6 \mathrm{mn}$. conf. "Mathematical modeling in ecology" EcoMatMod., pp. 187-189 (Pushchino, 2019)

2. A.V. Shklyar et al., Visual modeling of multidimensional data, Dynamics of systems, mechanisms and machines, 1(5), 125-128 (2017)

3. A.C. Bury, E.V. Morin, Cognitive model for assessing the quality of information technology, Information and economic aspects of standardization and technical regulation, 1(41) (2018)

4. S.N. Lapshina, D.B. Berg, I.A. Bazhenov, A.D. Denisov, V.A. Shaposhnikov, T.I. Yakovleva, Simulation models in economics to study scenarios for the development of economic systems,
Economics and management in mechanical engineering, 1, 41 (2016)

5. I. Furtat, E. Fridman, A. Fradkov, Disturbance Compensation with Finite Spectrum Assignment for Plants with Input Delay, IEEE Trans. Autom. Control, 63(1), 298-305 (2018)

6. N. Shmatko, G. Volkova, Service or devotion. Motivation patterns of Russian researchers, Foresight and STI Governance, 11(2), 54-66 (2017)

7. K.S. Ginsberg, To the foundations of the methodology of structural identification for the purpose of designing technical systems, in: Proceedings of $8^{\text {th }}$ All-Russian meeting on management problems, pp. 11-13 (IPU, Moscow, 2019)

8. B.V. Kostrov, R.V. Khrunichev, Development of an algorithmic structure for organizing search in small local databases, Bulletin of the Tula State University. Series Technical sciences, 9 (Part 1), 104-110 (2017)

9. A.V. Shklyar, Assessment of the practical applicability of visual research tools, Bulletin of the Bryansk State Technical University, 1(74), 69-76 (2019)

10. A.V. Shklyar, The effectiveness of visual analysis in decision-making problems, Information and Mathematical Technologies in Science and Management, 3(11), 147-155 (2018)

11. E. Pei, J. Jiang, Performance Analysis of LicensedAssisted Access to Unlicensed Spectrum in LTE Release 13, IEEE Trans. Veh. Technol., 68(2), 1446-1458 (2019)

12. S. Asta, D. Karapetuan, A. Kheiri, E. Özsan, A.J. Parkers, Combining monte-carlo and hyperheuristic methods for the multi-mode resourceconstrained multi-project scheduling problem, Information Sciences, 373, 476-498 (2016)

13. P. Kutsevol, V. Loginov, E. Khorov, A. Lyakhov, Analytical Study of License Assisted Access in $5 G$ Networks, in: Proc. IFIP Networking Conf., pp. 2251 (2019)

14. A.V. Shklyar, A.A. Zakharova, E.V. Vekhter, A comprehensive criterion for the applicability of visual analytics in expert systems, Information and mathematical technologies in science and management, 3(11), 37-44 (2018) 